\title{
Design of Heat Pipe Heat Exchanger with Plate Fins by two Methods LMTD and $\varepsilon$-NTU
}

\author{
Majid Lotfi ${ }^{1}$, Ali Kargar $^{2}$
}

\begin{abstract}
In this study, the effective factors on the heat transfer and pressure drop in heat pipe heat exchanger design based on the LMTD and effectiveness-NTU has been investigated. Increasing fuel cost and energy conservation, fuel consumption and also, pollution air are the most important consideration to be taken in new heat exchanger design, and modern compact heat exchangers. This paper describes a theoretical method to the design and performance of heat pipe heat Exchanger. Design of heat pipe heat exchanger for identifying of the principal parameters, which can optimize the performance of heat exchanger. Heat pipe heat exchanger efficiency with copper pipes is $10 \%$ higher than steel but steel pipe for strength and its ability to heat recovery of hot gases is preferred. Increasing the number of rows of tubes will increase efficiency. The largest diameter pipes and increasing the number of fins improved efficiency. Pressure drop of the heat pipe heat exchanger placed as heat recovery unit in hot gas duct of boilers and furnace depends on velocity and it is very important.
\end{abstract}

Keywords- Heat Pipe, Design of Heat Exchanger, LMTD and \&-NTU method, Pressure Drop

\section{Introduction}

At present, several methods exist for the transfer of heat between the hot and cold fluid. One of the ways that today's attention is heat pipe heat exchanger. Heat pipe heat exchanger is one of the most effective and efficient way for heat transfer. This heat exchanger made of heat pipe or thermosyphon. So that a heat pipe or thermosyphon heat exchanger such as components becomes part of the evaporator, condenser and working fluid is made. In HPHE heat pipe heat exchanger, heat from hot fluid to cold fluid by evaporation and condensation and heat the working fluid in individual tubes or thermosyphones be transferred. The main objective to design a heat exchanger is, first the heat exchanger to provide necessary heat transfer and second, the pressure drop over the heat exchanger and other connections in the flow direction of an economically constrained not exceed the limit. In general, the design and calculation of heat exchangers are divided into two categories. Categories in which issues first heat exchanger type and size are known, and the main issue was to determine the type of heat transfer and fluid outlet temperatures and intake temperatures is based on flow.

1- Majid Lotfi (corresponding author to provide)

Department of Chemical Engineering, Quchan Branch, Islamic Azad University, Quchan, Iran

\section{2- Ali Kargar}

Department of Mechanical Engineering, Quchan Branch, Islamic Azad University, Quchan, Iran
Categories in which issues first heat exchanger type and size are known, and the main issue was to determine the type of heat transfer and fluid outlet temperatures and intake temperatures is based on flow. These types of heat exchangers are known to performance issues.Categories in which issues second the flow rate and inlet and outlet temperatures of hot and cold fluid given. The design is to choose suitable exchangers, determine its size and calculate the surface needed to achieve the desired outlet temperature. After computing thermal energy there is the mechanical design. In this paper the exchangers design is performance and includes the following steps $[1,2]$ :

- Determine the type and size of the heat exchanger. At this stage surfaces are determined.

- Calculate thermal resistance and overall heat transfer coefficient.

- Calculate outlet temperatures and heat transmitted by two methods $\varepsilon$-NTU and LMTD.

\section{Heat Pipe Heat Exchanger Design Steps}

\section{A. Choose Size and Surface of Heat Exchanger}

At this stage exchanger surface characteristics with respect to the definition of the problem and accordingly determined in accordance with Table 1 [2-4].

TABLE I. THE PHYSICAL CHARACTERISTICS OF THE HEAT PIPE HEAT EXCHANGER

\begin{tabular}{|l|l|}
\hline Physical dimensions of exchangers & $\begin{array}{l}\text { Height }(\mathrm{H}), \text { Length }(\mathrm{L}), \text { Width } \\
(\mathrm{W})\end{array}$ \\
\hline $\begin{array}{l}\text { Physical dimensions of the heat pipe, } \\
\text { material and working fluid }\end{array}$ & $\begin{array}{l}\text { In and Out Diameter }\left(\mathrm{D}_{\mathrm{i}}, \mathrm{D}_{\mathrm{o}}\right), \\
\text { Length }(\mathrm{L}), \text { Copper and Water }\end{array}$ \\
\hline \multirow{2}{\text{Typesoffins}}{} & $\begin{array}{l}\text { Plate, thickness }\left(\mathrm{t}_{\mathrm{f}}\right), \text { number } \\
\left(\mathrm{n}_{\mathrm{f}}\right), \text { distance }\left(\mathrm{S}_{\mathrm{f}}\right), \text { Length }\left(\mathrm{l}_{\mathrm{f}}\right) \\
\text { Aluminum }\end{array}$ \\
\hline Pipe arrangement & $\begin{array}{l}\text { Staggered, Longitudinal pitch } \\
\left(\mathrm{S}_{\mathrm{L}}\right), \text { Traverse pitch }\left(\mathrm{S}_{\mathrm{T}}\right)\end{array}$ \\
\hline $\begin{array}{l}\text { The number of rows and the total } \\
\text { number pipe }\end{array}$ & $\mathrm{N}=\mathrm{N}_{\mathrm{L}} * \mathrm{~N}_{\mathrm{T}}$ \\
\hline
\end{tabular}

\section{B. Hot and Cold Fluid Properties}

At this stage, the physical properties of the hot gases entering the evaporator and cold air entering the condenser at the average temperature determined. It is necessary to determine the properties as primary assumption, outlet temperatures guessed [5].

$c_{p}=0.219+0.342 \times 10^{-4} T-0.293 \times 10^{-8} T^{2}$ 
$\mu=2.27 \times 10^{-8}\left(\frac{T^{1.5}}{T+198.7}\right) \times 32.2 \times 3600$

$K=\left(c_{p}+0.0857\right) \mu$

$\rho=\frac{M P}{R T}$

\section{Calculation of Reynolds number, Stanton - Colburn factor and Velocity in Evaporator and Condenser Section}

Reynolds number flow of hot gases entering the evaporator and cold air entering the condenser is calculated as follows [6].

$$
\begin{aligned}
& \operatorname{Re}_{L}=\frac{G S_{L}}{\mu} \\
& G=\frac{\dot{m}}{A_{c}} \\
& A_{c}=\left[\left(N_{T}-1 / 2\right)\left(S_{T}-D_{o}\right)\left(1-t_{f} n_{f}\right) L_{e}\right] \\
& \begin{array}{l}
u=\frac{G}{\rho} \\
j=
\end{array} \\
& j=\operatorname{St} \cdot \operatorname{Pr}^{2 / 3} \operatorname{Re}_{L}^{-0.35} \\
& S t=\frac{h}{\rho u c_{p}} \\
& \operatorname{Pr}=\frac{\mu c_{p}}{k}
\end{aligned}
$$

Calculation external convective heat transfer coefficient:

$h=\frac{j \rho u c_{p}}{\operatorname{Pr}^{2 / 3}}=\frac{0.195 \operatorname{Re}_{L}^{-0.35} \rho u c_{p}}{\left(\frac{\mu c_{p}}{k}\right)^{2 / 3}}=0.195 \operatorname{Re}_{L}{ }^{-0.35} \rho u c_{p}^{1 / 3} \mu^{-2 / 3} k^{2 / 3}$

Substituting physical properties, heat transfer coefficient in the evaporator and condenser section is determined.

\section{Calculation of Fin Efficiency}

Evaporator section with subtitles e (the condenser section relationships like this are part and only with subtitles c):

$$
\begin{aligned}
& \eta_{e, o}=1-\frac{A_{f e}}{A_{e o}}\left(1-\eta_{f e}\right) \\
& A_{f e}=2 N\left[S_{L} S_{T}-\frac{\pi}{4} D_{o}^{2}\right] n_{f} L_{e} \\
& A_{e o}=\left[2\left(S_{L} S_{T}-\frac{\pi}{4} D_{o}^{2}\right) n_{f}+\left(1-t_{f} n_{f}\right) \pi D_{o}\right] N L_{e}
\end{aligned}
$$

Where $A_{f e}$ is the total surface of fin in evaporator section and $A_{e o}$ is the total surface of heat transfer in the evaporator section.

$$
\begin{aligned}
& \eta_{f e}=\frac{\tanh \left(m l_{f}\right)}{m l_{f}} \\
& m=\sqrt{\frac{2 h_{e o}}{K_{f} t_{f}}} \\
& l_{f}=\frac{S_{L}}{2}
\end{aligned}
$$

\section{E. Calculation of Overall Heat Transfer Coefficient}

Heat pipe heat exchanger can be considered as a thermal resistance network. For evaporator and condenser section as below calculated [7-9].

$$
\begin{aligned}
& (U A)_{e}=\left[\frac{1}{\eta_{e o} h_{e o} A_{e o}}+\frac{1}{2 \pi K_{p} L_{e}} \ln \left(\frac{D_{o}}{D_{i}}\right)\right]^{-1} \\
& R_{e o}=\frac{1}{\eta_{e o} h_{e o}} \\
& R_{e p}=\frac{A_{e o}}{2 \pi K_{p} L_{e}} \ln \left(\frac{D_{o}}{D_{i}}\right) \\
& (U A)_{t}=\left[\frac{1}{\eta_{e o} h_{e o} A_{e o}}+\frac{1}{2 \pi K_{p} L_{e}} \operatorname{Ln}\left(\frac{D_{o}}{D_{i}}\right)+\frac{1}{2 \pi K_{p} L_{c}} \operatorname{Ln}\left(\frac{D_{o}}{D_{i}}\right)+\frac{1}{\eta_{c o} h_{c o} A_{c o}}\right]^{-1}
\end{aligned}
$$

\section{F. Calculation Temperatures of and \\ Outlet Transfer rate}

- $\quad$ LMTD method

$Q_{t}=U_{t} A_{t} \Delta T_{m}$

$Q_{h}=\left(\dot{m} c_{p}\right)_{h}\left(T_{h, \text { in }}-T_{h, \text { out }}\right)$

$Q_{c}=\left(\dot{m} c_{p}\right)_{c}\left(T_{c, \text { out }}-T_{c, \text { in }}\right)$

If $\dot{m}_{h}$ and $\dot{m}_{c}$ are known with regard to the relationship $Q_{h}=Q_{c}=Q_{t}$, three unknowns $T_{c, \text { out }}, T_{h, \text { out }}, Q_{t}$ are calculated by solving simultaneous equations.

$$
\begin{aligned}
& T_{h, \text { out }}=T_{h, \text { in }}-\frac{Q_{t}}{\left(\dot{m} c_{p}\right)_{h}} \\
& T_{c, \text { out }}=T_{c, \text { in }}+\frac{Q_{t}}{\left(\dot{m} c_{p}\right)_{c}} \\
& Q_{t}=U_{t} A_{t} \frac{\left(T_{h, \text { in }}-T_{c, \text { out }}\right)-\left(T_{h, \text { out }}-T_{c, \text { in }}\right)}{\ln \frac{T_{h, \text { in }}-T_{c, \text { out }}}{T_{h, \text { out }}-T_{c, \text { in }}}}
\end{aligned}
$$

Substituting the equation (27) and (28) in (29) we have:

$$
Q_{t}=\frac{\left(T_{h, i n}-T_{c, i n}\right)\left(1-\exp \left[U_{t} A_{t}\left(\frac{1}{\left(\dot{m} c_{p}\right)_{h}}-\frac{1}{\left(\dot{m} c_{p}\right)_{c}}\right)\right]\right)}{\frac{1}{\left(\dot{m} c_{p}\right)_{c}}-\frac{1}{\left(\dot{m} c_{p}\right)_{h}} \exp \left[U_{t} A_{t}\left(\frac{1}{\left(\dot{m} c_{p}\right)_{h}}-\frac{1}{\left(\dot{m} c_{p}\right)_{c}}\right)\right]}
$$

Outlet temperatures can be corrected by guessed temperatures in the physical properties. 
Proc. of Fourth International Conference On Advances in Civil, Structural and Mechanical Engineering - ACSM 2016 Copyright (c) Institute of Research Engineers and Doctors, USA .All rights reserved.

ISBN: 978-1-63248-096-5 doi: 10.15224/ 978-1-63248-096-5-13

- $\quad \varepsilon-N T U$ method [7-9]

$$
\begin{aligned}
& N T U_{h}=\frac{(U A)_{h}}{C_{h}} \\
& C_{h}=\left(\dot{m} c_{p}\right)_{h} \\
& N T U_{c}=\frac{(U A)_{c}}{C_{c}} \\
& C_{c}=\left(\dot{m} c_{p}\right)_{c} \\
& \varepsilon_{h}=1-\exp \left(-N T U_{h}\right) \\
& \varepsilon_{c}=1-\exp \left(-N T U_{c}\right) \\
& \varepsilon_{p}=\left(\frac{1}{\varepsilon_{\min }}+\frac{C}{\varepsilon_{\max }}\right)^{-1} \\
& \varepsilon=\frac{\left(\frac{1-C \varepsilon_{p}}{1-\varepsilon_{p}}\right)^{n}-1}{\left(\frac{1-C \varepsilon_{p}}{1-\varepsilon_{p}}\right)^{n}-C} \\
& \varepsilon=\frac{\left(\dot{m} c_{p}\right)_{h}\left(T_{h, \text { in }}-T_{h, \text { out }}\right)}{\left(\dot{m} c_{p}\right)_{\min }\left(T_{h, \text { in }}-T_{c, \text { in }}\right)}=\frac{\left(\dot{m} c_{p}\right)_{c}\left(T_{c, \text { out }}-T_{c, \text { in }}\right)}{\left(\dot{m} c_{p}\right)_{\min }\left(T_{h, \text { in }}-T_{c, \text { in }}\right)} \\
& T_{h, \text { out }}=T_{h, \text { in }}-\varepsilon_{p} \frac{\left(\dot{m} c_{p}\right)_{\min }}{\left(\dot{m} c_{p}\right)_{h}}\left(T_{h, \text { in }}-T_{c, \text { in }}\right) \\
& T_{c, \text { out }}=T_{c, \text { in }}-\varepsilon_{p} \frac{\left(\dot{m} c_{p}\right)_{\min }}{\left(\dot{m} c_{p}\right)_{c}}\left(T_{h, \text { in }}-T_{c, \text { in }}\right)
\end{aligned}
$$

These temperatures can be corrected by guessed temperatures in the physical properties. The difference between the amount of heat transfer calculated by the two methods LMTD and $\varepsilon$-NTU and the desired value (defining the problem), by reducing or increasing the number of tubes and fins and overall geometry Exchangers is minimal.

\section{Calculation of Pressure Drop}

$\Delta P=\Delta P_{n o n-f i n}+\Delta P_{f i n}$

Where $\Delta P_{n o n-f i n}$ is the pressure drop of tube bundle without fins and $\Delta P_{f i n}$ is the pressure drop caused by fins.

$$
\begin{aligned}
& \Delta P_{\text {non-fin }}=N_{L} \chi f\left(\frac{\rho u_{\mathrm{max}}^{2}}{2}\right) \\
& \operatorname{Re}_{\text {max }}=\frac{\rho u_{\text {max }} D_{o}}{\mu} \\
& f=\left[1+\frac{0.47}{\left(\frac{S_{T}}{D_{o}}-1\right)^{1.08}}\right] \operatorname{Re}_{\text {max }}^{-0.16} \\
& \Delta P_{\text {fin }}=f_{f}\left(\frac{A_{f}}{A_{c}}\right) \frac{G^{2}}{2 \rho} \\
& f_{f}=1.7 \operatorname{Re}_{L}^{-0.5}
\end{aligned}
$$

\section{Iv. Result}

Heat pipe heat exchanger design to determine the main parameters that can optimize the performance of this exchanger. Based on the design done in this paper it is studied the effects of various factors on exchanger efficiency. The plot of the efficiency of the evaporator and condenser velocity in two parts for copper and steel tubes in Fig 1, Variation of efficiency on heat pipe and the number of rows in Fig 2, Variation of efficiency of the heat pipe diameter and number of fins in Fig 3 and Variation of pressure drop and fluid velocity of the hot and cold sides of the evaporator and condenser in Fig 4 is displayed.

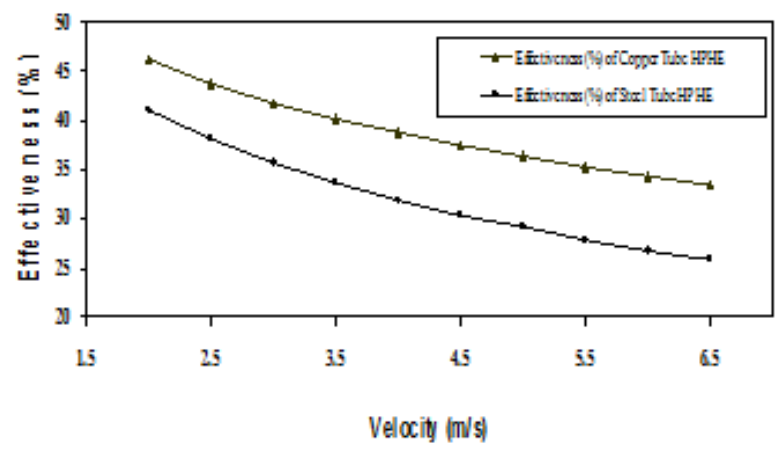

Figure 1. Variation efficiency than velocity in copper and steel heat pipe

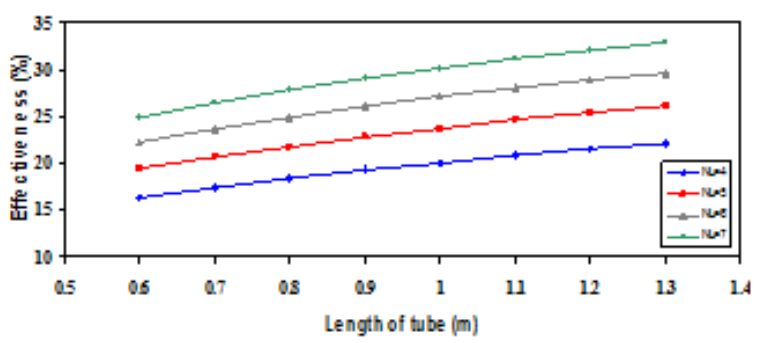

Figure 2. Variation of efficiency on heat pipe and the number of rows

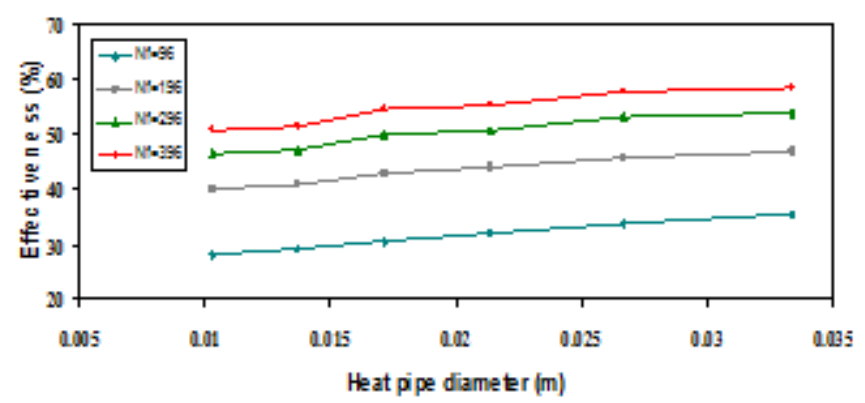

Figure 3. Variation of efficiency of the heat pipe diameter and number of fins 
Proc. of Fourth International Conference On Advances in Civil, Structural and Mechanical Engineering - ACSM 2016

Copyright (c) Institute of Research Engineers and Doctors, USA .All rights reserved.

ISBN: 978-1-63248-096-5 doi: 10.15224/ 978-1-63248-096-5-13

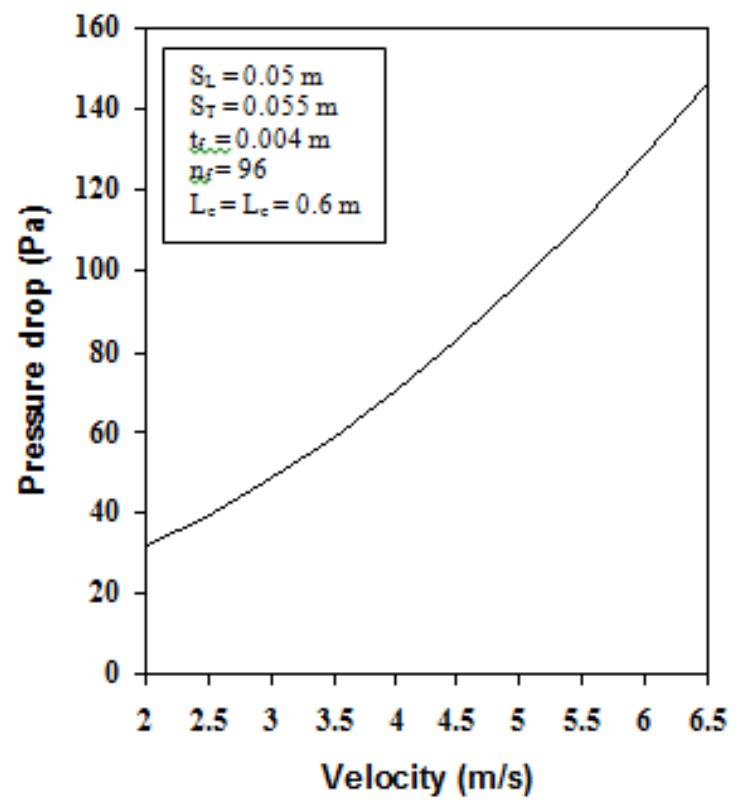

Figure 4. Variation of pressure drop and fluid velocity of the hot and cold sides of the evaporator and condenser

\section{v. Conclusion}

The base design and diagrams shown, the effect of the main factors in optimizing heat pipe heat exchanger performance includes:

- Heat pipe heat exchanger efficiency with copper pipes from 33.4 to $46.1 \%$, which is about 10 percent higher than steel. The heat transfer rate is higher in copper pipes. Although the efficiency of copper pipes is higher, but are limited in temperatures above $200{ }^{\circ} \mathrm{C}$. Therefore, taking into account the working pressure safety and limit, type of steel pipe for strength and its ability to heat recovery of hot gases is preferred.

- In a mass flow rate specified maximum length and increasing the number of rows of tubes will increase efficiency.

- The largest possible diameter pipes and increasing the number of fins for improved performance and efficiency during Pipe length.

- The pressure drop of the heat pipe heat exchanger in the flow direction with increasing velocity directly related to the hot gas in boilers and furnace flue is important.

\section{References}

[1] Faghri, A. "Heat Pipe Science and Technology", Taylor \& Francis, USA, 1995

[2] Kays, W.M., and London, A.L., "Compact Heat Exchanger Design", 3rd. Ed., McGraw Hill, New York, 1984

[3] Dube, V., Sauciuc, I., and Akbarzadeh, A., "Design Construction and Testing of a Thermosiphon Heat Exchanger for Medium Temperature
Heat Recovery", Proc. 5th Int. Heat Pipe Symposium, Melbourne, Australia, 1996

[4] Sun, J.Y. and Shyu, R.J., "Waste Heat Recovery Using Heat Pipe Heat Exchanger for Industrial Practices", Proc. 5th Int. Heat Pipe Symposium, Melbourne, Australia, 1996

[5] Feldman, K.T., Lu, D.C., "Preliminary Design Study of Heat Pipe Heat Exchangers", Proc. 2nd Int. HPC, Italy, ESA Report SP112. Vol. 1., pp. 451-461, 1976

[6] Azad, E., Geoola, F., “A Design Procedure for Gravity-assisted Heat Pipe Heat Exchanger”, Heat Recovery System, Vol. 4, No. 2, Britain, pp. 101-111, 1984

[7] Azad, E., Bahar, F., Moztarzadeh, F., "Design of Water-to-Air Gravity-Assisted Heat Pipe Heat Exchanger", Heat Recovery System, Vol. 5, No. 2, Britain, pp. 89-99, 1985

[8] Noie, S.H. and Lotfi, M. “ Energy Conservation by Waste Heat Recovery in Industry Using Thermosyphon Heat Exchangers ", International Solar Energy Society, ISES Conference, Australia, November, 2001

[9] Incorpera, F.P. and DeWitt, D.P., "Fundamentals of Heat and Mass Transfer", 3rd Ed, John Wiley and Sons, Toronto, 1996 